\title{
Prediction of FRP Debonding Using the Global-Energy-Balance Approach
}

\author{
Chris J. Burgoyne ${ }^{1}$, P. Mithila. M. Achintha ${ }^{2}$, Garfield X. Guan ${ }^{3}$ \\ ${ }^{1}$ Dept of Engineering, University of Cambridge, Cambridge,UK, cjb@eng.cam.ac.uk \\ ${ }^{2}$ Dept of Eng. Science, University of Oxford, Oxford, UK, mithila.achintha@eng.ox.ac.uk \\ ${ }^{3}$ Dept of Engineering, University of Cambridge, Cambridge, UK, xgg20@cam.ac.uk
}

SYNOPSIS:

A major research programme was carried out to analyse the mechanism of FRP debonding from concrete beams using global-energy-balance approach (GEBA). The analyses developed in the study provide an essential tool that will enable fracture mechanics to be used to determine the load at which FRP plates will debond from concrete beams. This obviates the need for finite element (FE) analyses in situations where reliable details of the interface geometry and crack-tip stress fields are not attainable for an accurate analysis. This paper presents an overview of the GEBA analyses that is described in detail elsewhere, and explains the slightly unconventional assumptions made in the analyses.

Keywords: Branson's model, external strengthening, fracture mechanics, FRP, interface debonding, mixed-mode crack 
Chris J. Burgoyne is Head of the Structures Group at the University of Cambridge. He has carried out extensive research into the use of advanced fibres for use in a variety of Civil, Structural and Marine applications. He has published extensively and was a founder member of ACI 440.

Mithila Achintha is a post-doctoral research assistant in the Department of Engineering Science, University of Oxford, UK. He received his BSc(Eng) from the University of Moratuwa, Sri Lanka and PhD from University of Cambridge, UK in 2003 and 2010 respectively. His research interests include the application of fibre-reinforced polymers in civil engineering and fracture mechanics of concrete.

Garfield X. Guan is a PhD student at the University of Cambridge. He received his B.Eng. degree in Civil Engineering from the University of Hong Kong. He is currently studying the application of concrete fracture mechanics in RC structure retrofitting, and he has wider research interests in RC structures and seismic engineering.

\section{INTRODUCTION}

A comprehensive study of the debonding of FRP plates from concrete beams using the global-energy-balance approach (GEBA) has been undertaken; many of the concepts used have been described in elsewhere e, $2,3,4^{\text {. This }}$ paper summarises the overall logic but space does not permit a detailed discussion of the individual elements.

A high stress may cause a crack to form near the interface between the concrete and the FRP, but that crack will only propagate if more energy is thereby released than it takes to form the new fracture surfaces. It is thus a fracture mechanics problem, not a stress-analysis problem. The Global Energy Balance Approach to the study of debonding of FRP plates from concrete beams is a very simple concept, but requires understanding of some complex mechanics. When a crack forms, the beam loses some of its stiffness so the load does more work; most of which is stored by an increase in strain energy within the beam. So to calculate the energy that is released these two quantities have to be calculated with reasonable accuracy.

This paper addresses a number of issues that are important in the analysis of debonding of FRP plates from concrete beams. The evaluation of energy states in cracked concrete beams using the stress-strain $(\sigma-\varepsilon)$ behaviour over the whole beam is very complex, so in the present model a simpler integration of moment-curvature $(M-\kappa)$ is used, but even determining the curvature is complex. Branson's model ${ }^{5}$ was conceived only for beams with conventional steel reinforcement, and only up to the point where the steel yields. When external FRP is added there is an additional layer of reinforcement, with different bond characteristics so it is incorrect to incorporate the FRP as a second layer of steel reinforcement in the Branson's model. The model also has to be applicable after the steel has yielded. The present paper shows how these issues have been addressed.

The debonding analyses rely on knowing the fracture energy of concrete $\left(G_{C}\right)$, a parameter that is easy to define but less easy to determine, and one that is rarely assessed in experimental studies, even if it is the most important concrete parameter when studying debonding. Unlike glass, the fracture process zone (FPZ) in concrete is large, typically over $300 \mathrm{~mm}(1 \mathrm{ft})$ long, and may have a width of several times the aggregate size. Conventional fracture analysis would require modelling the whole of this zone, but a debonding fracture occurs in a narrow zone of the concrete cover that has FRP on one side and the steel rebar on the other (Fig. 1a). Propagation of a short crack is unlikely to allow the FPZ to develop fully. The present GEBA analyses rely on the fact that fracture energy is not affected by the length of the debonding crack; this is discussed.

Premature FRP debonding hampers efficient use of externally bonded FRP plates in flexural strengthening of reinforced concrete $(\mathrm{RC})$ beams, and uncertainty about the governing mechanisms means that there is no reliable theory that can be applied by designers. The earlier work of the present authors has shown that the area near the plate end, and zones where widening of flexural cracks causes interface flaws, are those most susceptible to the initiation of debonding; (Fig. 1b) the two modes are referred to as "plate-end" (PE) and "intermediate-crackinduced" (IC) debonding respectively ${ }^{3}$. PE debonding initiates from the vicinity of the plate end and propagates towards the mid-span of the beam, whereas IC debonding initiates at a high-moment zone and propagates towards a low-moment zone (Fig. 1b). It has also been shown that the present GEBA model can be used to analyse debonding of steel plates provided that the plates remain within elastic limits. 


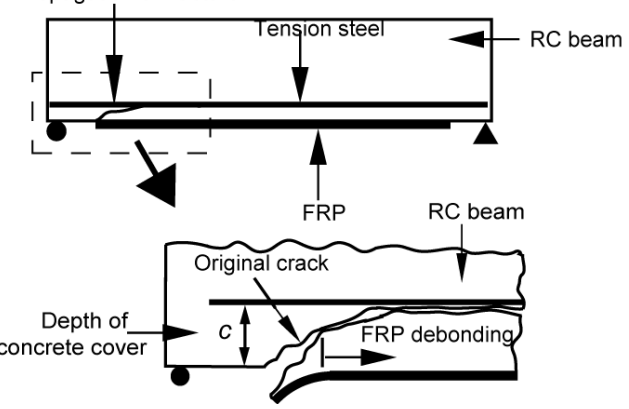

(b)

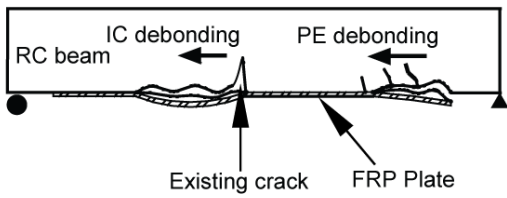

Figure 1. - (a) Debonding propagates in the concrete just above the interface (b) PE and IC debonding

Manufacturers have now developed adhesives that are sufficiently tough that, if used correctly, debonding usually takes place in the concrete beam just above the interface (Fig. 1a). It has been observed that FRP debonding initiates from the propagation of a dominant crack in the vicinity of the interface, and hence, fracture-mechanicsbased analyses have often been used in the literature to determine failure loads. However these analyses, (for example Günes $^{6}$ ) were often based on the pioneering theories of Hutchinson and Suo ${ }^{7}$, which were intended for the analysis of interface debonding in thin-layered elastic materials. Because of the long FPZ associated with fractures in concrete, a reliable solution for FRP debonding cannot be obtained from the theories of linear-elastic-fracturemechanics (LEFM). Furthermore, the non-linear FE models, such as the J-integral method, that would be needed to simulate the debonding of FRPs, require far more detail of the interface properties than will ever be available, even to the analyst of laboratory experiments, and certainly not to designers. Most analyses reported in the literature have only been calibrated against individual researchers' own, usually limited, test data, and none of these analyses has received a wide acceptance.

There is a need for a more physically-based fracture mechanics model that represents energy balance requirements, rather than an unreliable analysis of crack-tip stress field. The model has to be based on governing parameters that can be reliably determined and should be able to analyse all modes of debonding in beams with a wide range of dimensions. The earlier work of the present authors has shown that the energy states in beams can be determined to an accuracy good enough for models of RC beams, and the incorporation of these energy estimates in the GEBAbased debonding model correlated well with test data reported in the literature ${ }^{3}$. The work obviates the need for unreliable FE analyses which have often been used in the studies reported in the literature.

The "current state" of a system will be at a position of minimum total potential energy. The GEBA model determines that debonding will occur if the energy available for a potential small extension of an existing interface crack exceeds the energy needed to form the new fracture surfaces formed during this crack propagation. If the energy release rate $\left(G_{R}\right)$ associated with an existing crack exceeds the fracture energy of concrete $\left(G_{C}\right)$ the crack will propagate. How the initial crack developed up to the current state is immaterial and it is sufficient to assume that flaws of the relevant size are likely to exist in critical locations. The model can be used to determine the shortest crack that triggers failure at a given load and also the failure load of a beam with an existing crack of known length ${ }^{3}$.

However, determinations of both $G_{R}$ and $G_{C}$, either theoretically or experimentally, are complex even in a research context; the present study has developed appropriate methods to calculate both the parameters to an accuracy that is reliable enough to be used in the analysis of FRP debonding. The $G_{R}$ associated with a given crack can be determined by considering the energy changes that take place in the system during a potential unit extension of the crack. However, this analysis is not trivial; integration of $M-\kappa$ relationships determined on the assumptions that the section is uncracked (i.e. concrete in the tension zone is fully effective) significantly underestimates the energy state of the beam, while if the beam is assumed to be fully-cracked (i.e. no tensile contribution from concrete) the energy state is significantly overestimated. Various tension-stiffening models exist, although these were primarily developed to calculate the deflections of RC beams. Branson's model ${ }^{5}$ indirectly incorporates the effects of tensionstiffening into the stiffness of cracked RC beam sections by defining an effective stiffness in the deflection analysis of conventional RC beams (i.e. with steel reinforcement only) and the model has been widely verified in the 
literature. In the present work the model has been modified to take account of several factors so that it can be used for the energy analysis of strengthened beams ${ }^{2}$.

Fracture propagates in the concrete substrate, so it is necessary to know $G_{C}$ of the concretes from which the beams are made. In different modes of fracture (i.e. opening; shear; or a combination of both), different stress-displacement fields will develop in the vicinity of the crack, so it is necessary to determine $G_{C}$ corresponds to the correct fracture mode. The present study has shown that the interface of a strengthened beam, which is primarily carrying shear, actually fails in tension. The relative vertical displacements between the two crack faces of the original shear crack and the difference in the curvatures between the RC beam and the FRP at the plate end introduce significant peeling (tensile) stresses in the vicinity of the interface flaw that causes PE debonding (Fig. 2a). During IC debonding, the force in the FRP $\left(F_{p}\right)$ acts with an eccentricity with respect to the tip of the interface crack and induces significant tension at the crack tip (Fig. 2b). The fracture propagates locally by opening (i.e. as a Mode I crack $)^{4}$. The work has also shown that the results of shear-lap experiments, which have often been reported in the literature in studies of FRP debonding, only provide an estimate for the shear mode fracture energy which is not relevant for the debonding analyses. The incorporation of the Mode I fracture energy of concrete $\left(G_{C I}\right)$ in the debonding analyses provided results that match with test data reported in the literature ${ }^{3}$. The present paper explains why particular values for $G_{C I}$ have been chosen in that study.

(a)
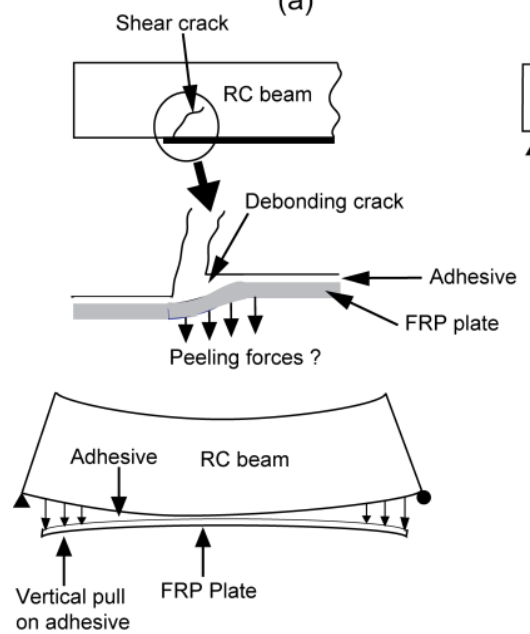

(b)

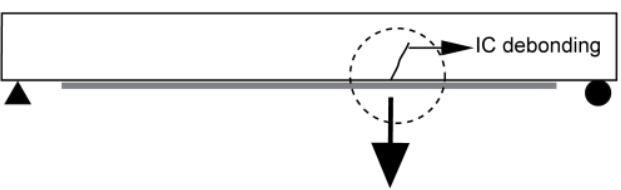

Tension in the crack tip due to $F_{p}$

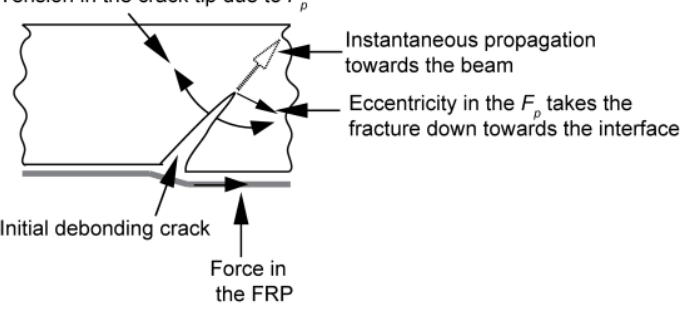

Figure 2. - Tensile stresses of significant magnitudes are developed in the crack tip

(a) PE debonding (b) IC debonding

\section{MECHANISM OF FRP DEBONDING}

PE debonding forms when an interface crack forms due to the widening of a shear crack in the vicinity of the plate end, whereas IC debonding is triggered by an interface crack formed due to the widening of a critical flexural crack in the high moment zone (Fig. 1b). Shear and peeling stress concentrations develop due to geometric restraints and also due to the relative vertical movements of the faces of the critical shear/flexural crack, which triggers further propagation of the already-formed interface crack, causing separation of FRP from the concrete beam ${ }^{4}$.

The whole concrete cover of the beam usually separates during PE debonding, whereas a concrete layer of only a few millimetres thick separates during IC debonding 9 . This observation has led some researchers to analyse PE debonding as a shear failure of the RC beam and IC debonding as an interface failure ${ }^{9}$. However, both modes are essentially fractures in the concrete substrate and the difference in the fracture path is due to the effect of the difference in the magnitudes of force in the FRP $\left(F_{P}\right)$ in the corresponding locations. The principal interfacial stress in the vicinity of the debonding crack will be at about $45^{\circ}$ to the interface, and thus it is expected that the crack will move into the beam. PE-debonding cracks usually move up to the level of tension steel bars and the final failure 
occurs at this level. However, during IC debonding, the large force $F_{p}$ that acts eccentrically to the crack tip takes the fracture back down towards the interface, and debonding propagates in the concrete just a few millimeters above the interface (Fig. 2). The present GEBA model has been used to analyse the both modes of FRP debonding ${ }^{3}$.

Experimental studies reported in the literature suggest that PE debonding is the likely failure mode of most strengthened beams ${ }^{9}$, and hence, a number studies investigated the effectiveness of the use of plate-end anchoring systems (e.g. FRP jackets ${ }^{8}$ ) and the use of long FRP plates right up to the beam end ${ }^{10}$ as methods to resist PE debonding. Although the methods improved the strength and the ductility of beams, the fact that PE debonding still takes place may be due to the stress concentrations developed due to the anchoring devices. The use of long FRPs usually eliminated PE debonding, but this can lead to premature IC debonding ${ }^{10}$.

\section{ANALYSIS OF FRP DEBONDING USING GEBA METHOD}

Fracture mechanics investigates the possible propagations of existing cracks and it better simulates the mechanism of interface debonding than any other method. Even though numerous cracks are inevitably present in the interface between the FRP and the concrete, most are either not long enough, or not weak enough to trigger failure. Only the propagation of a dominant crack triggers failure and it is this that is analysed by the GEBA method. Analytical methods that compare interfacial stress concentrations with the interface strength might not be able to distinguish the critical crack that triggers debonding from other minor flaws. Conventional fracture mechanics analyses that determine $G_{R}$ at the crack tip, such as the $\mathrm{J}$ integral method, cannot be performed because the microstructure in the vicinity of the interface is unknown. Nonlinear finite element packages use special types of element to model crack tips and the FPZ, such as collapsing elements to model stress singularity at a crack tip and special "spring" type elements that can incorporate the effects of the cohesive forces in the FPZ. However, because of the heterogeneous nature of concrete the details can never be known in sufficient detail, even for laboratory specimens, let alone when designing a new structure.

As an alternative, the present GEBA model predicts FRP debonding by comparing two governing parameters $\left(G_{R}\right.$ and $G_{C I}$ ), both of which can be determined to an appropriate accuracy. An essential first stage of the calculation of $G_{R}$ associated with an existing crack, is the determination of the energy state of the beam at a given applied load, derived using an appropriate $M-\kappa$ model that is discussed below.

Moment-curvature analysis of strengthened beams

Although the analysis of a RC beam section with the assumptions that the section was uncracked or fully-cracked is straightforward, an accurate $M-\kappa$ analysis of a partially-cracked section whilst incorporating the effects of tension-stiffening of cracked concrete is not trivial. Branson's model (Eq. 1) incorporates the effects into the section's stiffness indirectly by defining an effective stiffness $\left(I_{e f f}\right)$ as an interpolation between those of the uncracked $\left(I_{u n}\right)$ and fully-cracked $\left(I_{f c}\right)$ sections, primarily with a view to being able to predict the deflections of beams $\left(I_{u n}\right.$ and $I_{f c}$ can be determined to an acceptable accuracy from an elastic and a cracked-elastic analysis respectively). The interpolation coefficient ( $K$ in Eq. 1) takes account of the current cracking level of the section and is defined as the ratio between the moment that causes the first flexural crack in the section $\left(M_{c r}\right)$ and the current applied moment $\left(M_{a p p}\right)$. The model has been widely validated against experimental results of deflections of RC beams, and also, with appropriate modifications, the method has been used in the analyses of prestressed concrete beams ${ }^{11}$.

$$
I_{\text {eff }}=K I_{u n}+(1-K) I_{f c} \quad \text { where } \quad K=\left(M_{c r} / M_{a p p}\right)^{4}
$$

$I_{\text {eff }}$ in Eq. (1) is the effective second moment of area of the equivalent transformed concrete section of modulus $E_{c}$, so curvature of the section $(\kappa)$ can be determined as:

$$
\kappa=M_{\text {app }} /\left(E_{c} I\right)
$$

\section{A modified Branson's model for strengthened beams}

In a strengthened beam, the $M-\kappa$ relationships of uncracked/fully-cracked sections can be determined as those of a conventional beam whilst taking account of the effect of the force in the FRP $\left(F_{p}\right)$. The objective is to use the Branson's concept to determine stiffness and hence the curvature in a partially-cracked section and is discussed 
below. However, the original Branson's model will need modifying here because it is not correct to consider FRP as a second layer of internal steel reinforcement and it is also necessary to consider the strain state when the FRP is partially debonded. The earlier work of the present authors ${ }^{2}$ has shown that, if the effect of $F_{P}$ was incorporated as an external prestressing force on the RC beam alone, the analyses can be simplified conceptually since it allows analysing the RC beam portion as a conventional beam (Fig. 3). However, this complicates the analysis since now it requires analysing the $\mathrm{RC}$ section for a combined action of a compressive force and moment, both acting at the section's centroid. At any given location along the beam, the moment due to the applied load is generally known $\left(M_{a p p}\right)$. This acts on the combined beam section (i.e. RC beam section + FRP plate). The portion of this applied moment which is resisted by the RC section alone $\left(M_{\text {eff }}\right)$ can be determined if the location of the centroid is known. The energy in the RC beam can be then determined as $\int_{L} M_{\text {eff }} \kappa d x+\int_{L} F_{p} \varepsilon_{0} d x$ ( $\kappa-$ curvature, $\varepsilon_{0}-$ strain in the beam section at the location of centroid and $L$ - beam span). The determination of the energy in the FRP is trivial since FRP is assumed to be linear elastic. The separation of the energies due to moment and force in this way is only valid if the actions are calculated relative to the section's centroid, the determination of which is discussed below.

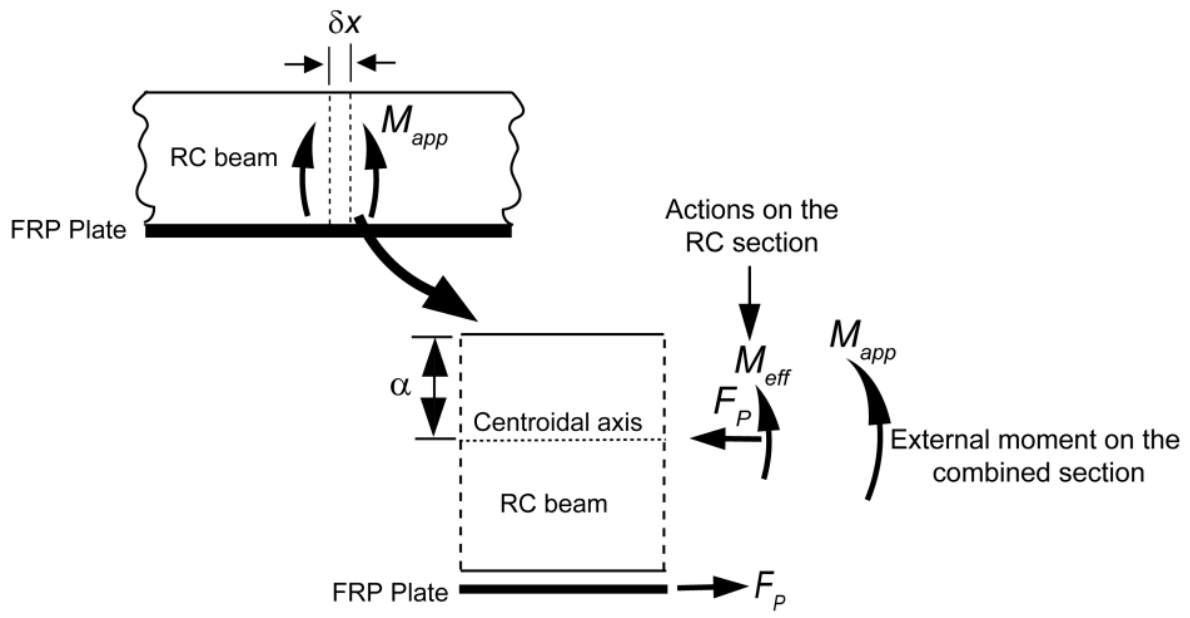

\section{Complexities over conventional Branson analysis}

The original Branson's model only applies to RC beams subject to pure bending, which can be regarded as a simple couple, so there is no need to define a particular reference axis. This will no longer be true in the analysis of strengthened beams because the RC section has to be analysed under $M_{\text {eff }}$ and $F_{p}$ (Fig. 3). The modification of Branson's model to take account of the effects of the axial force is discussed below.

\section{Force in the FRP}

Branson's original model is only concerned with stiffness and is not used to determine the strains in the beam that are assumed to be adequate because separate checks (either permissible stress or section strength) would be performed in association. However, in a strengthened beam, if the FRP is bonded to the beam section then the strain in the FRP is locally compatible with that in the extreme tension fibre of the RC section, and if the FRP is partly debonded over a zone in the beam span, then the extension of the FRP over the unbonded region is compatible with that of the extreme tension fibre of the RC beam over the same zone ${ }^{2}$. The new model, therefore, requires the satisfaction of a compatibility condition between the FRP and the concrete, which means strong assumptions need to be made about the strains, and hence stresses, in the beam section; these have to be determined from the effective stiffness. As a result, $F_{P}$ at a given location in the beam span cannot be known a priori, so it is treated as a variable and determined numerically using a least-squares method ${ }^{2}$. Once an accurate value for $F_{p}$ is known, all other parameters may be evaluated. 
Location of equivalent centroid

It is impossible to find an axis in a cracked $\mathrm{RC}$ beam section that satisfies the requirements of centroid in a linear elastic analysis (i.e. $F_{p}=\int_{A} \sigma d A$ and $M_{e f f}=\int_{A} \sigma y d A$ where $A$ is the cross sectional area and $y$ is the distance from

the centroid; strain energy given by $\left.\int_{L} M_{\text {eff }} \kappa d x+\int_{L} F_{p} \varepsilon_{0} d x\right)$. The concept was thus developed of an "equivalent centroid" $(\alpha)$ of strengthened RC beam sections that will allow the separation of $M_{\text {eff }}$ and $F_{p}$ approximately, and hence, to determine the energy state in the usual way to an accuracy good enough to be used in the debonding analyses $^{2}$. For uncracked and fully-cracked sections the $\sigma-\varepsilon$ distributions are reliably known from respective section analyses, and hence, the relevant equivalent centroids can be determined by considering the equivalent transformed sections ( $\alpha_{u n}$ and $\alpha_{f c}$ respectively), whilst taking account of the secant modules of non-linear materials. The centroidal location of a partially-cracked section $\left(\alpha_{\mathrm{eff}}\right)$ will then be interpolated between respective $\alpha_{u n}$ and $\alpha_{f c}$ using Branson's concept; this analysis is presented elsewhere ${ }^{2}$. It should also be noted that the materials are non-linear, and the secant modulus varies with stress, and hence, the location of $\alpha$ changes with the applied load. Thus, there is no fixed centroid that is a section property.

\section{$\underline{\text { Modified interpolation coefficient }}$}

When the amount of cracking of a RC section increases, the tension-stiffening effects eventually become ineffective. In Branson's model, however, the stiffness in the section becomes asymptotic to the fully-cracked state but never reaches it. That model was intended to represent sections at working loads and well below yield of the steel bars. However, the fully-cracked state will be reached in strengthened beams because that is why they needed strengthening in the first place. In the present model, it was assumed that a beam section will be fully-cracked at the moment that causes first yielding of tension steel $\left(M_{y}\right)$; and the interpolation coefficient $\left(K_{p}\right)$ is determined by considering the magnitudes of $M_{c r}, M_{y}$ and $M_{a p p}{ }^{2}$. This modification does not cause significant changes to the predictions from the original model for conventional RC beams but avoids a discontinuity in stiffness when the steel yields (an example is shown in Fig. 4).

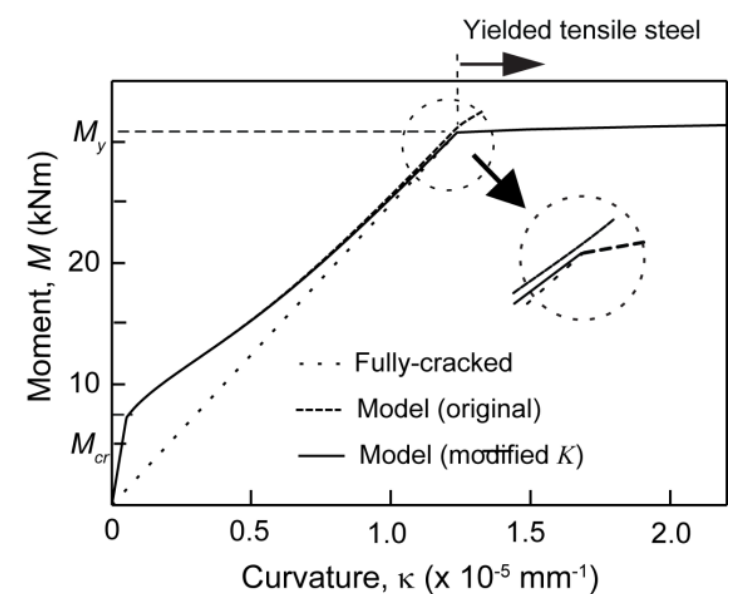

Figure 4. - For a conventional RC beam, the model predictions with the assumption of the fully-cracked state at $M_{y}$ do not cause significant changes to the results at moments below $M_{y}$ (Curvature $-1.10^{-5} \mathrm{~mm}=2.5 .10^{-4} \mathrm{ins}$; Moment $-10 \mathrm{kNm}=7376 \mathrm{ft}-\mathrm{lbs}$ )

As a further complication, because of the presence of the axial load, the effective moment acting on the RC section alone depends on the choice of the axis about which it acts. The obvious choice would be the centroid, but as shown above this is not at a fixed location, either along the beam or as the loading increases. To avoid complications, it was decided to use a fixed axis about which to calculate the effective moment used to determine the interpolation factor $K_{p}$; the mid-depth axis of the beam was chosen, the corresponding moments are $M_{c r-m}, M_{y-m}$, and $M_{\text {eff-m }}$ respectively (Eq. 3).

$$
K_{p}=\left(M_{c r-m} / M_{e f f-m}\right)^{4}\left[1-\left\{\left(M_{a p p-m}-M_{c r-m}\right) /\left(M_{y-m}-M_{e f f-m}\right)\right\}^{4}\right]
$$


Equivalent elastic stiffness

As discussed previously, $M_{\text {eff }}$ and $\kappa$ of uncracked and fully-cracked sections can be directly determined from respective section analyses. The objective is to use Branson's concept to determine effective stiffness and hence $\kappa$ of partially-cracked sections. Since the present model is to be applied to sections where the nonlinearity of material behaviour needs to be taken into account, the cracked-elastic analysis used in the Branson's model is not applicable. Since the Young's modulus of concrete is no longer fixed, there is no value in defining an equivalent second moment of area. Instead, an equivalent elastic stiffness $(B)$ is defined in place of the product of $E_{c}$ and $I$ used in the original model. The values of $B$ for uncracked and fully-cracked sections ( $B_{u n}$ and $B_{f c}$ respectively) can be determined from the direct section analyses ${ }^{2}$. For a partially-cracked section, the corresponding $B_{u n}$ and $B_{f c}$ are first calculated, and that of the actual section $\left(B_{\text {eff }}\right)$ is then interpolated (Eq. 4). The location of $\alpha_{\text {eff }}$ and hence $M_{\text {eff }}$ of the actual section is known so combining $M_{\text {eff }}$ with $B_{\text {eff }}$ the $\kappa$ of the section can be determined (Eq. 5). Flowcharts of the complete process of determining $M_{\text {eff }}$ and $\kappa$ of sections with bonded or partially debonded FRPs are shown in Fig. 5 (a) and (b) respectively.

$$
\begin{gathered}
B_{e f f}=K_{p} B_{u c}+\left(1-K_{p}\right) B_{f c} \quad \text { where } K_{p} \text { is from Eq. (3) } \\
\kappa=M_{\text {eff }} / B_{\text {eff }}
\end{gathered}
$$

(a)

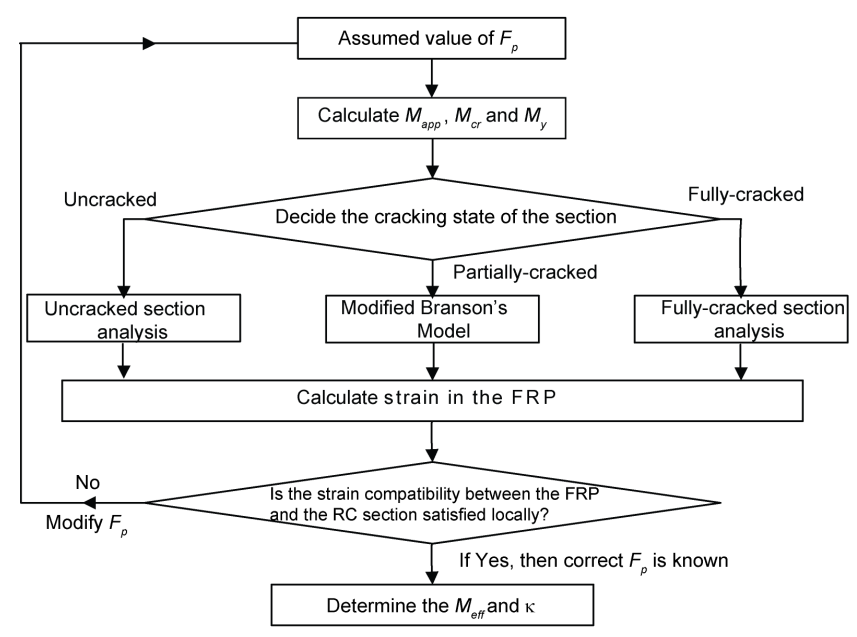

(b)

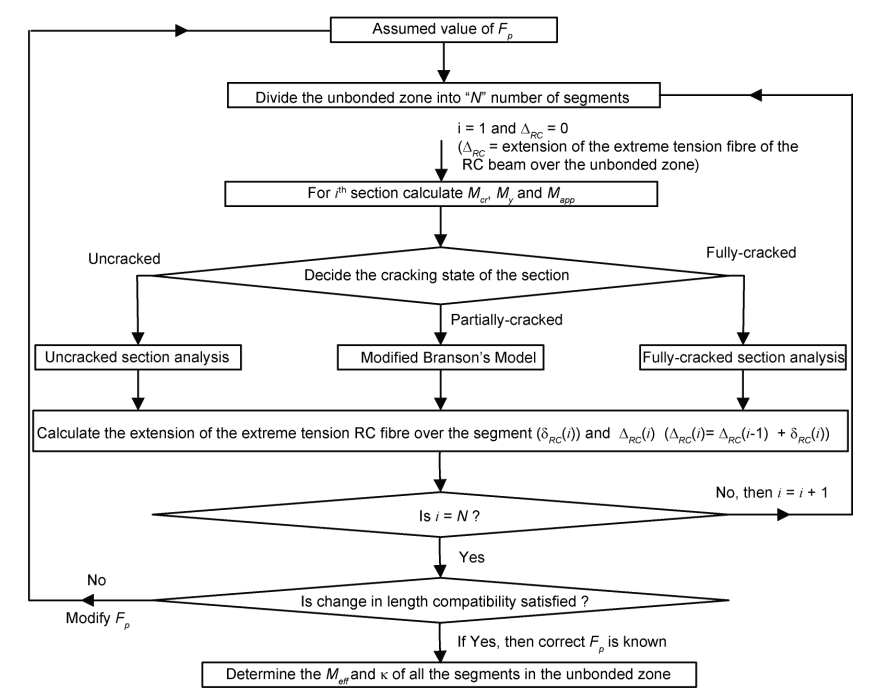

Figure 5. - Step-by-step procedure to calculate $M_{\text {eff }}$ and $\kappa$ in sections with (a) fully-bonded (b) unbonded FRP

The $M-\kappa$ model was applied to several sets of beam tests reported in the literature and the model was found to be accurate enough for a model of RC beams ${ }^{2}$. All the beams analysed in the study were tested as simply-supported beams and a large database of specimens, including a variety of material/geometric properties, was investigated. The axial force in the beam can be either externally applied or exists due to unbalanced stress resultants acting on the RC section as in the case of strengthened beams. Comparisons with the test data and the present model were made under both of these categories. The model was also used to determine strain and deflection profiles of strengthened beams. A single example for each of $M-\kappa$ and strain profile comparison in strengthened beams are shown in Fig. 6. 
(a)

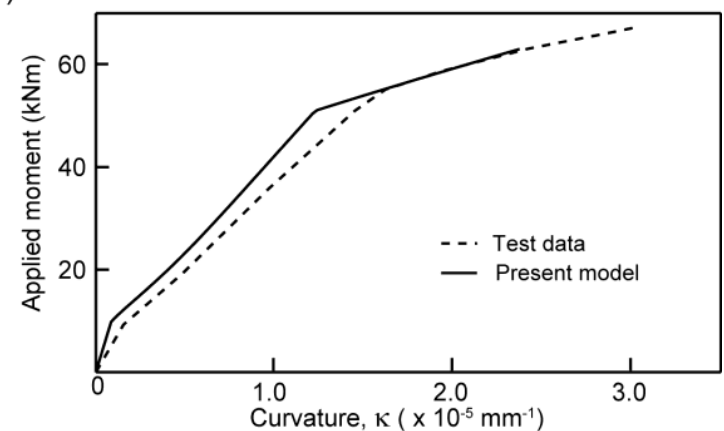

(b)

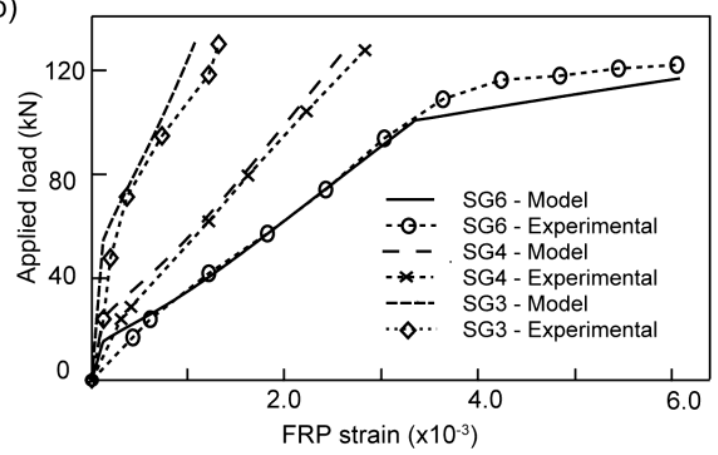

Figure 6. - (a) M- $\kappa$ comparison for Beam A3.1 ${ }^{12}$ (b) FRP strain comparisons along the span of Beam CB4-2S ${ }^{13}$ (Curvature $-1.10^{-5} \mathrm{~mm}=2.5 .10^{-4} \mathrm{ins}$; Force $-100 \mathrm{kN}=22500 \mathrm{lbs}$; Moment $-10 \mathrm{kNm}=7376 \mathrm{ft}-\mathrm{lbs}$ )

Fig. 6a shows $M-\kappa$ comparisons for a strengthened beam (Beam A3.1) tested by Spadea et al. (1998). It shows that the model can successfully predict behaviour for all uncracked, partially-cracked, and fully-cracked regimes. The predicted $M_{c r}$ and $M_{y}$ are slightly higher than those actually observed, which may be attributed to the overestimation of the concrete tensile strength or the yield strength of steel. The small variations in the stiffness predictions may be attributed to a slight overestimation of the material stiffness. Comparisons with the measured strains in the FRP at three different span locations in Beam CB4-2S tested in four-point bending by Alagusundaramoorthy et al. ${ }^{13}$ are shown in Fig. 6b. Locations SG6, SG4 and SG3 quoted in the figure correspond to positions in the constant moment zone, centre region of one of the shear spans and at distance one quarter of the shear span from the beam support, respectively. Good correlations can be observed in all cases. This shows that, not only does the present model correctly predict the curvatures, but it also correctly predicts the neutral axes, from which it can be assumed that the strain profiles will be correct.

\section{DETERMINATION OF $\mathrm{G}_{\mathrm{R}}$ ASSOCIATED WITH EXTENSION OF AN INTERFACE CRACK}

In the GEBA model the $G_{R}$ associated with a small potential extension of a given interface crack is required to compare with $G_{C I}$ to decide whether the crack will propagate. The objective is to use the present $M-\kappa$ model to determine $G_{R}$ at a given applied load. When the crack extends, the beam loses some of its stiffness, so work is done by the external loads. The curvature increases in the beam, storing some of this extra work as strain energy, but some is left over to cause the crack to propagate. Thus, according to the global energy balance of the system, the $G_{R}$ is the rate of change of the system's total potential energy, $\Pi_{s y s}$ (i.e. the sum of the potential energies in the applied loads $\left(W_{\text {load }}\right)$ and the work done on the beam $\left(W_{\text {beam }}\right)$ ) with respect to the crack length $(a)$ (Eq. 6).

$$
G_{R}=-1 / b_{p}(\partial \Pi / \partial a)=-1 / b_{p}\left(\partial W_{\text {beam }} / \partial a+\partial W_{\text {ext }} / \partial a\right) \quad\left(b_{p}=\text { width of the FRP }\right)
$$

In order to focus on the basic mechanics, analysis of a simply-supported beam is assumed in the present discussion. The procedure would need modifying if a statically indeterminate beam was to be analysed when the distribution of moments caused by applied loads would change as the beam's stiffness changes during crack extension. When a RC beam bends, a part of the energy put into the beam by the loads is dissipated in cracking and 
steel yielding. The rest is stored as the beam's strain energy, shown schematically in Fig. 7. It is not correct to determine $G_{R}$ simply as the rate of change of strain energy, as is usually done in a LEFM analysis where it is assumed that the total work done on the beam by the loads is stored as strain energy. A number of existing FRP debonding analyses, however, are based on this incorrect theory ${ }^{6}$.

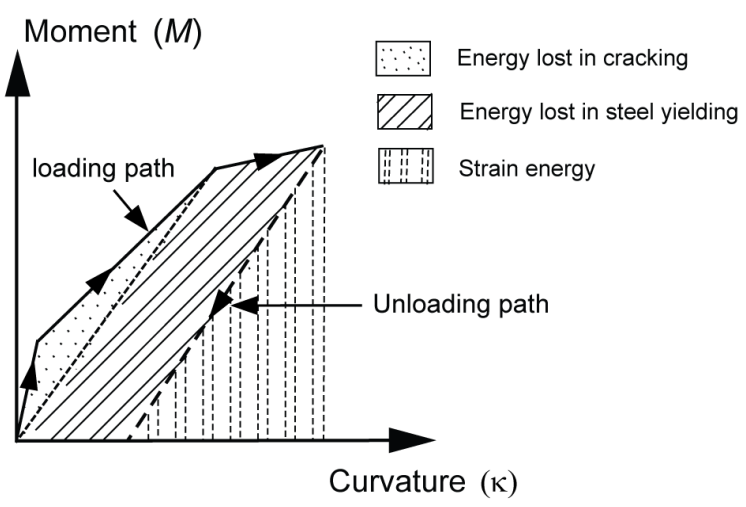

Figure 7. - Only a part of the total work done is stored as beam's strain energy

\section{The method used to calculate $G_{R}$}

$G_{R}$ is determined as the change in system's total potential energy $(\Delta \Pi)$ per unit area of new interface crack $\left(G_{R}\right.$ has the units N/mm). Due to the crack extension, the beam softens, but not uniformly. Over most of the length of the beam the curvature and hence the strain energy remain unchanged; it is only the portion of the beam near the crack tip where significant changes of curvature occur ${ }^{1}$.

(a)

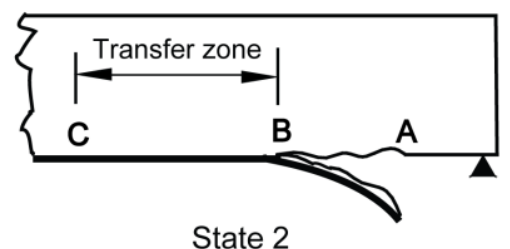

State 2

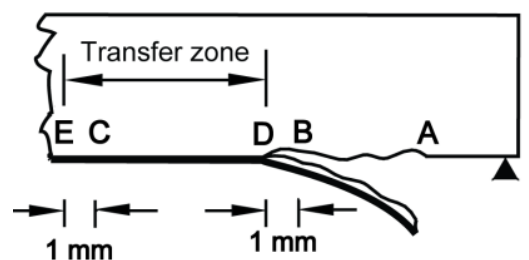

(b)

State 1

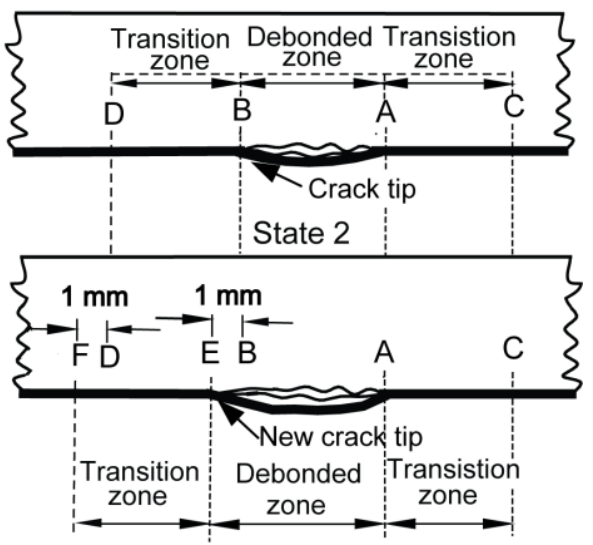

Figure 8. - Energy released zones: before (State 1) and after (State 2) small crack extension (a) PE debonding (b) IC debonding extension

$G_{R}$ associated with PE debonding is determined by considering the energy and $\mathrm{\kappa}$ changes take place in beam segments within the plate-end transfer zone (BE in Fig. 8a); for IC debonding $\kappa$ changes take place in the unbonded zone and the two transition zones (CF in Fig. 8b). Outside these zones, the FRP is fully-bonded to the concrete, so if the load does not change during the debonding increment, the moment and hence the curvatures remain constant.

It is important to know the length of the transition zone. A simplified model, based on the more rigorous interfacial stress analysis of Täljsten ${ }^{14}$, was used to determine the distribution of $F_{p}$ in the plate-end stress transfer zone and also that in the transition zones associated with an existing IC debonding crack $^{1}$. The results show that the length of each of this stress-transfer zone is about 30 times the thickness of the FRP for most FRP/adhesive/concrete combinations; this value is used in all subsequent analyses. 
$\underline{\text { Calculation of } G_{\underline{R}}}$

The objective is to determine the $\Delta \Pi$ (i.e. the sum of the additional work done on the beam $\left(\Delta W_{\text {beam }}\right)$ and the change in the potential energy of externally applied loads $\left(\Delta W_{e x t}\right)$ due to the assumed small crack extension) by using the present $M-\kappa$ model. Only the changes in the energy state and $\kappa$ in the critical zone (Fig. 8) are considered. The critical zone is first divided into segments $1 \mathrm{~mm}$ long and the additional work done $\left(\delta W_{\text {beam }}\right)$ and the change in curvature $(\delta \kappa)$ in each segment after the assumed crack extension are calculated as shown below. The $\delta W_{\text {beam }}$ in each segment is then summed to obtain $\Delta W_{\text {beam }}$. By numerically integrating $\delta \kappa$ of individual beam segments, the change in deflection profile and hence $\Delta W_{\text {ext }}$ can be calculated.

Calculation of $\Delta W_{\text {beam }}$ - Due to the crack extension, both the effective moment $\left(M_{\text {eff }}\right)$ and the axial force $\left(F_{p}\right)$ in RC segments alter and there will also be a change in the strain energy in the FRP. According to the present $M-\kappa$ model, the $\delta W_{\text {beam }}$ in a beam segment consists of three components: additional work done in the RC section due to the change in $M_{\text {eff }}\left(\delta W_{M}\right)$, additional work done in the RC section due to change in $F_{p}\left(\delta W_{F}\right)$ and change in strain energy in the FRP $\left(\delta W_{F R P}\right)$. Fig. 9 shows the changes in all these three action-deformation relationships in a beam segment, with the assumption that all have increased during the transformation. All $M, \kappa, F_{p}$ and $\varepsilon_{0}$ of the segment before and after the crack extension (i.e. States 1 and 2 respectively) can be calculated from the $M-\kappa$ model, and hence, $\delta W_{\text {beam }}$ and $\Delta W_{\text {beam }}$ can be determined:

$$
\delta W_{\text {beam }}=\delta W_{M}+\delta W_{F}+\delta W_{F R P} \text { and } \Delta W_{\text {beam }}=\sum_{\text {critical zone }} \delta W_{\text {beam }}
$$

(a)

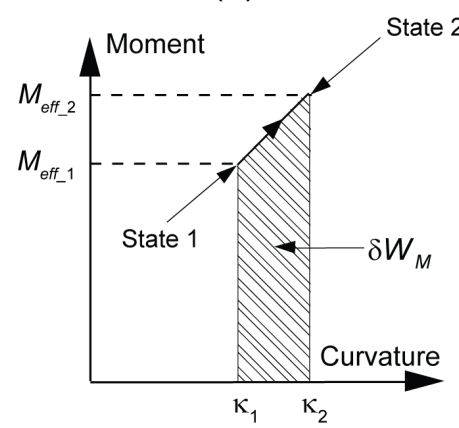

(b)

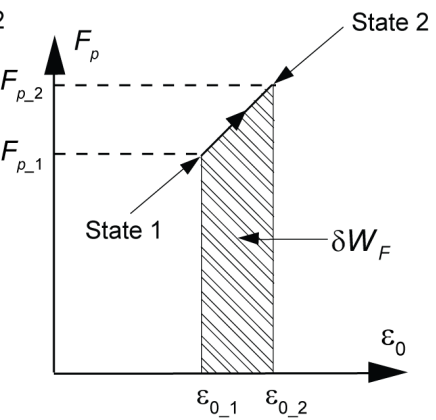

(c)

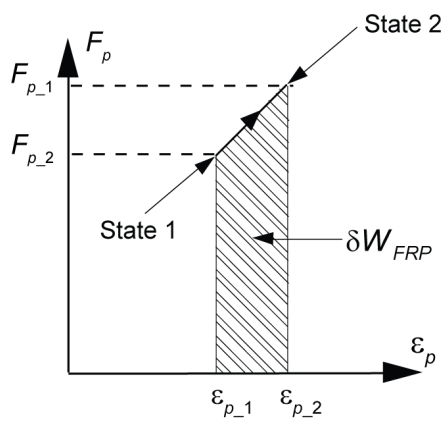

Figure 9. - Changes in the actions of a beam segment due to the crack extension (a) moment (b) axial force acting in the concrete beam section and (c) in the FRP plate

Calculation of $\Delta W_{e x t}-$ By numerically integrating $\delta \kappa$ in the beam sections within the critical zone, the change in beam's deflection profile $\left(\Delta_{\text {dis }}\right)$ and hence the $\delta W_{\text {ext }}$ can be determined (Fig. 10).

$$
\Delta W_{\text {ext }}=\sum_{\text {forall loads }} P \Delta_{\text {dis }} \quad \text { where } P \text { is the applied load }
$$

Finally $G_{R}$ can be calculated:

$$
\left.G_{R}=-1 / b_{p}\left(\Delta W_{\text {beam }}+\Delta W_{\text {ext }}\right) \quad \text { (typically, } \Delta W_{\text {ext }}<0\right)
$$


Validation of $G_{\underline{R}}$ calculated from the $M-\kappa$ model against that from direct $\sigma-\varepsilon$ analyses

Figure 10. - Change in potential energy of the applied loads

Since accurate $\sigma-\varepsilon$ relationships cannot be developed to model tension-stiffening effects, it is impossible to verify the present $M-\kappa$ model generally, but if a case is considered in which the debonding takes place either in a region which is completely uncracked or in a region which is fully-cracked, the "exact" $G_{R}$ value can be determined from direct $\sigma-\varepsilon$ integration, so the error in the results calculated from $M-\kappa$ integration can be investigated. Fig. 11 shows the $G_{R}$ values calculated from $M-\kappa$ and $\sigma-\varepsilon$ integrations respectively for an interface crack that initiated IC debonding in a typical beam, with all the sections in both unbonded and the transition zones are in the state of fullycracked. $G_{R}$ here can thus also be calculated from the integration of $\sigma-\varepsilon$ relationships. The figure shows that $G_{R}$ calculated from the $M-\kappa$ model agrees well with that from $\sigma-\varepsilon$ analysis with about $5 \%$ error, which is well below the variance of about $\pm 10 \%$ usually associated with experimentally determined $G_{C I}{ }^{15}$. Analysis of other beams 15 shows similar results.
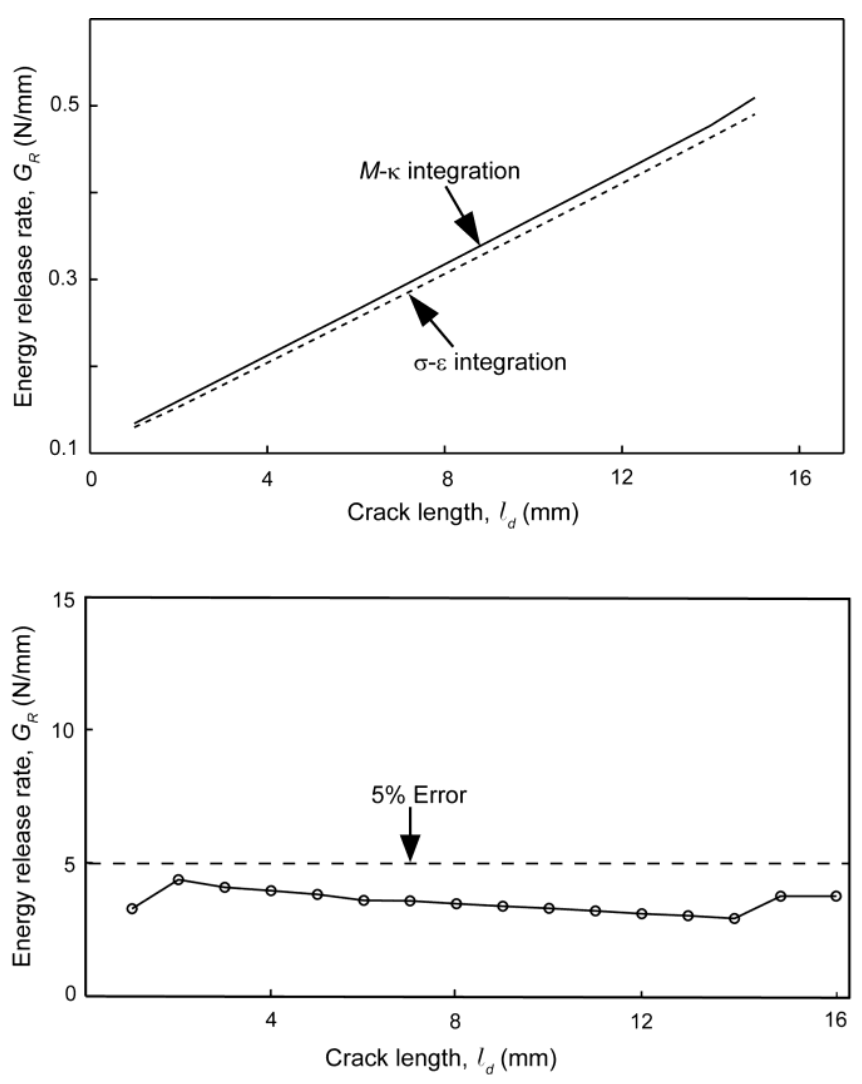

Figure 11. - (a) $G_{R}$ estimation from $\sigma-\varepsilon$ and $M-\kappa$ analyses (b) percentage error in $G_{R}$ calculated from $M-\kappa$ integration (a)

(b) 
Effect of tortuous crack paths

Due to the material heterogeneities and the complex crack-tip stress fields, an interface crack does not propagate on a unique plane, so the $G_{R}$ calculated as above represents the $G_{R}$ per unit area of crack projected onto the horizontal plane. Nevertheless, $G_{R}$ calculated this way can still be compared with $G_{C \text { I }}$, which is either experimentally determined or based on approximate theoretical models, both of which inevitably include accounts for tortuous crack paths and also for the development of new microcracks ${ }^{4}$. The present GEBA model only requires a reasonable estimate of $G_{C I}$, which is usually available, whereas a FE-based analysis would require accurate details of crack paths and the development of microcracks all of which are difficult to know with any certainty.

\section{INTERFACE FRACTURE ENERGY}

Debonding fracture usually takes place in the concrete substrate, and the $G_{C}$ in the vicinity of the interface depends on the mode of fracture. The present study has shown that FRP debonding can be regarded as a Mode I fracture in concrete, despite the interface being loaded primarily in shear ${ }^{4}$.

\section{The mechanism of fracture of concrete during FRP debonding}

The geometric restraints, and the relative vertical movements of the faces of the critical shear/flexural crack, cause significant shear and peeling stress concentrations in the vicinity of interface cracks. These subsequently trigger propagation of already formed cracks ${ }^{4}$. A crack will start to propagate by opening (i.e. Mode I fracture) in the direction perpendicular to that of the maximum principal tensile stress (MPTS). Since the principal stress would be at about $45^{\circ}$ to the interface, the crack would move into the beam. Usually, in PE debonding, the original interface crack moves up to the level of tension steel bars and the final failure occurs at this level (Fig. 2). However, during IC debonding, the $F_{P}$ which carries a high tension acts eccentrically to the tip of the crack, taking the fracture back down towards the interface, and hence, the fracture propagates close to the interface along a path approximately parallel to it. Based on the orientation of the fracture path, a number of studies reported in the literature wrongly modeled IC debonding as a shear fracture of concrete ${ }^{9}$. The high $F_{P}$ causes a significant tension in the crack tip causing opening of the crack tip - i.e. debonding locally propagates by Mode I. This can be further confirmed by the fact that, during IC debonding, the FRP remains attached to the RC beam at the other end of the original interface crack, and hence, the relative sliding between the two crack faces could not take place, and any movement of the crack faces must be normal to the crack tip.

\section{FRACTURE ENERGY OF CONCRETE AGAINST FRP DEBONDING}

The GEBA model relies on knowing the $G_{C}$ of concrete, which is rarely assessed in experimental studies, even though FRP debonding is clearly a fracture event.

A combination of normal and shear stress concentrations will be present in the vicinity of an existing interface crack. It might be supposed therefore that a mixed-mode fracture energy would be relevant. However, because of the relatively high shear fracture resistance of concrete, and also because crack plane separations with a magnitude similar to the size of the aggregate are required to activate shear fracture mechanisms, it is a reasonable approximation to assume that $G_{C}$ for mixed-mode fractures is dominated by the Mode I fracture energy $\left(G_{C I}\right)$, which is much less than the $G_{\mathrm{CII}}{ }^{4}$. This assumption has been widely validated in the literature in relating various other mixed-mode fracture problems ${ }^{16}$, and is also assumed in the present GEBA model. Details of experimental and theoretical investigations of $G_{C I}$ of concretes are presented elsewhere ${ }^{4}$; the methods by which the $G_{C I}$ values of the beams quoted in that study were determined and the values that results in are briefly discussed below.

\section{Determination of $G_{C I}$}

The stress vs. crack-separation relationships in the FPZ, which is required to determine $G_{C I}$, depend on many microstructural features such as size, shape, surface texture and location of the aggregate pieces, and also on the distribution of voids in the mix; no accepted direct method is quoted in the literature for this analysis. Although, a reliable estimate for $G_{C I}$ of a given concrete can be determined from experiments, the experimental investigations are often associated with practical and conceptual difficulties. Alternatively, simplified models, which are usually based on more readily known properties of concrete such as compressive strength $\left(f_{c}^{\prime}\right)$, size and type of the 
aggregate may be used to estimate $G_{C I}$ to an accuracy good enough for debonding analyses; in the present work, three widely quoted approximate simplified models and an empirical model reported in the literature were used to estimate $G_{C I}$ of the concretes used in the beams ${ }^{4}$.

Estimation of $G_{C \underline{L}}$ using simplified models

Approximate simplified models determine $G_{C I}$ as the work required to open the tip of a traction-free crack to a critical value where there are no stress transfers across the crack tip. The stress vs. crack-opening $\left(\sigma_{\Gamma}-w_{\mathrm{I}}\right)$ relationship at the crack tip is referred to as the tension softening response of concrete and is usually approximated by a bi-linear or a polynomial form. In the models quoted in the literature, the governing parameters of the $\sigma_{\mathrm{I}}-w_{\mathrm{I}}$ curve are represented in terms of tensile strength of concrete $\left(f_{t}\right)$, and the type and size of the largest aggregate. The area under the tension-softening curve is adjusted to match reliable estimates of $G_{C I}$ obtained from more accurate analyses or from experiments. The models can then be used to estimate $G_{C I}$ of other concretes.

$\underline{G}_{C I}$ values used in the comparisons with test data of FRP debonding

The GEBA-based FRP debonding analysis was applied to several sets of beam tests reported in the literature ${ }^{3}$. $G_{C I}$ values of the concretes used were not measured, so it is necessary to decide on values that can be used in the debonding analysis. The $f_{c}^{\prime}$ of the concretes used in the beams being tested were in the range $30-55 \mathrm{~N} / \mathrm{mm}^{2}$; (4. - 8. ksi) crushed aggregates of 20 and $10 \mathrm{~mm}$ and $10 \mathrm{~mm}(0.8$ and $0.4 \mathrm{ins})$ rounded aggregates were used in the mixes (the complete database can be found elsewhere ${ }^{4}$. The $G_{C I}$ of the beams under consideration, were calculated from concrete data quoted by the experimenters, according to the bi-linear tension-softening models of Guinea et al. ${ }^{17}$, and Gustafsson and Hillerborg ${ }^{19}$; and the polynomial model of Reinhardt ${ }^{18}$; and also using the empirical model of Bažant and Becq-Giraudon ${ }^{20}$. The results show that for a given concrete, the predictions from these models are very similar. Also, since $f_{c}^{\prime}$ of the concretes did not vary significantly, the variations in $G_{C I}$ of the beams mainly depend on the aggregate type and size ${ }^{4}$. Based on the model predictions, $G_{C \text { I }}$ of mixes with crushed aggregates of 20 and $10 \mathrm{~mm}$ and $10 \mathrm{~mm}(0.8$ and $0.4 \mathrm{ins})$ rounded aggregates were assumed to be $0.15,0.10$ and $0.07 \mathrm{~N} / \mathrm{mm}(0.85$, 0.57 and $0.40 \mathrm{lbs} / \mathrm{in}$ ) respectively. These values agree with experimentally obtained $G_{C I}$ values quoted in the literature for concretes with similar properties ${ }^{15}$. The experimentally determined $G_{C I}$ values were often associated with a scatter about $10 \%$, so results for a $\pm 10 \%$ variation in $G_{C I}$ was considered in the present debonding analyses.

\section{Effect of the length of short cracks on $G_{C I}$}

The earlier work of the present authors has shown that interface cracks of 10-30 mm (0.4-1.2 in) long cause PE debonding, whereas critical cracks with lengths less than $5 \mathrm{~mm}(0.2 \mathrm{in})$ trigger IC debonding ${ }^{3}$. The final issue in the discussion of $G_{C I}$ is whether the FPZ, which is typically over $300 \mathrm{~mm}$ long, will be fully developed during the propagations of these shorts cracks. Although reliable analyses exist for some non-linear materials (e.g. metals, FRPs) to study the fracture parameters associated with short cracks (i.e. R-curve analysis), a similar analysis of concrete is not trivial and no reliable models are quoted in the literature ${ }^{4}$. As a further complication, fracture occurs in a narrow zone of concrete between the FRP and the internal steel bars in the beam (Fig. 1a); the strain limit imposed by the steel bars almost certainly means that the FPZ cannot develop fully. However, measured values of $G_{C I}$ of concrete are usually obtained from small test specimens, where the FPZ could not fully develop. In addition, the present GEBA model considers the change in energy state for a short extension of the debonding crack. Any FPZ present in State 1 will be mirrored by a similar FPZ in State 2. Thus, it is assumed here that the same amount of energy is locked up in the two FPZs so that $G_{C I}$ is unaffected by the crack length. The use of $G_{C I}$, determined in this way, in the debonding analyses gives results that match the test data reported in the literature. A detailed study of a "typical crack", including the R-curve behaviour, is the subject of a new study.

\section{RESULTS OF FRP DEBONDING ANALYSES}

The predictions of the method have been compared with experiments reported in the literature. A number of test beams, including a variety of material/geometric properties, and covering beams that failed in all possible modes of debonding, was investigated. Comparisons made in this study show that the present model predicts results that match the test data ${ }^{3}$. A single example for each of PE and IC debonding are presented below.

\section{Example: PE debonding}

The critical shear crack that develops in the vicinity of the plate end usually propagates at about $45^{\circ}$ to the interface, up to the level of tension-steel bars (Fig. 12). The peeled part of the plate carries no force, so the effective 
plate end location $\left(L_{0} e\right)$ is now placed slightly away from the actual plate end location $\left(L_{0}\right)$. How far the initial shear crack develops prior to the attainment of the critical debonding state determines the location of $L_{0 \_} e$, which in turn governs the associated $G_{R}$. The variation between $L_{0}$ and predicted $L_{0} e$ is expressed in terms of the depth of the cover $(c)$ : results are normally fitted between $L_{0}-2 c$ and $L_{0}+2 c$. The best possible agreement between the model predictions and the experimental results would be for failure at $P=P_{f}$ (observed failure load); $G_{R}=G_{C I}$ (including a range with $\pm 10 \%$ variation in $G_{C I}$ ) to occur at the observed $L_{0 \_}$. Fig. 13 shows the variation in $G_{R}$ vs. $L_{0 \_}$for a pair of beams (F9 and F10) selected from the study of Fanning and Kelly ${ }^{21}$. The $G_{C \text { I }}$ of the concrete mix with $20 \mathrm{~mm}$ ( $0.8 \mathrm{in})$ crushed aggregate was assumed to be $0.15 \mathrm{~N} / \mathrm{mm}(0.85 \mathrm{lbs} / \mathrm{in})$. The figure shows that taking $L_{0 \_}$to be $10 \mathrm{~mm}(0.4 \mathrm{in})$ higher than the actual $L_{0}$ (i.e. $\left.L_{0}<L_{0} e^{<} L_{0}+c\right)$, the $P_{f}$ predicted from the model compares well with the observed $P_{f}$. The figure also shows that, at $P_{f}$, any $L_{0 \_}$shorter than the $L_{0}$ could not cause PE debonding, since an interface crack of a positive magnitude is required to trigger failure. Fig. 13 also shows that loads $10 \%$ higher/lower than $P_{f}$ are too strong/too weak respectively to cause failure within the range $L_{0}<L_{0} e<L_{0}+c$. Thus, the model predictions match with the observed $P_{f}$ and failure mode.
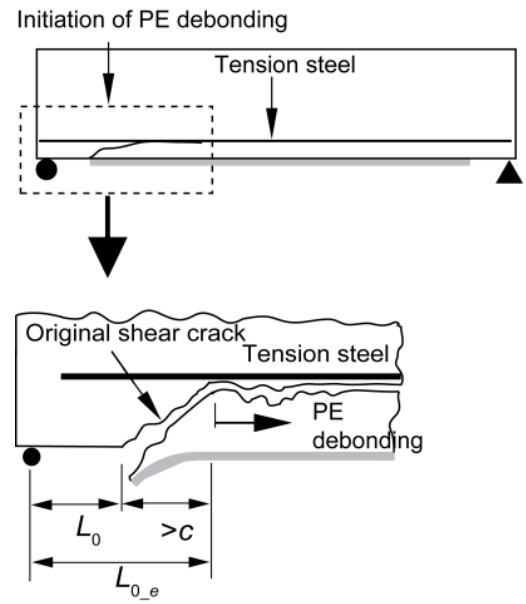

Figure 12 - Location of the effective plate end $\left(L_{0_{-} e}\right)$

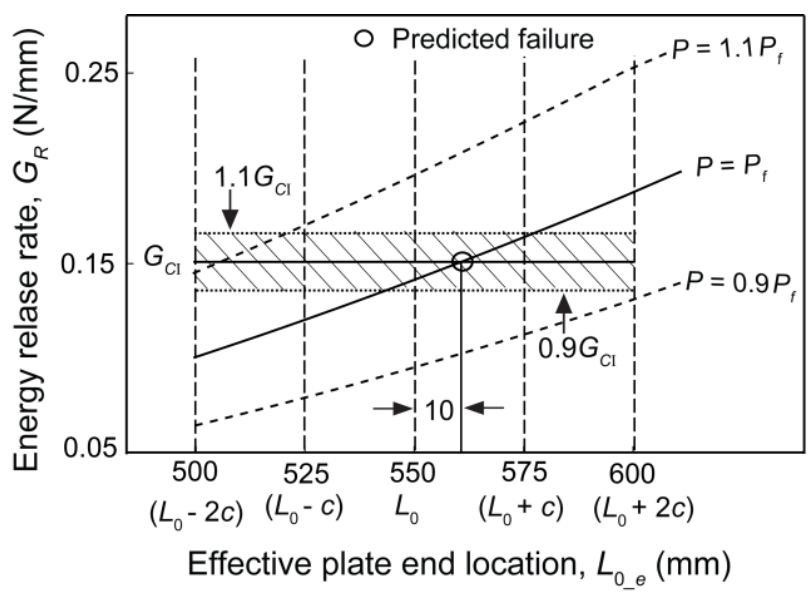

Figure $13-G_{R}$ vs $L_{0 \_}$plots for beam set F9 and F10 ${ }^{21}$

\section{Example: IC debonding}

Analyses have shown that, in four-point bend beams, interface cracks formed at about a half beam depth $(h)$ away from the loading point $\left(x_{c}\right)$ cause IC debonding (Fig. 14) $)^{3}$. Analysis of the failure observed in a set of beams (Group 1) reported in the study of Ross et al. ${ }^{10}$ is discussed here. Possible propagations of interface cracks that are assumed to initiate at $x_{c}$ and, further distances $1 / 2 h$ and $h$ towards the nearest beam end were investigated. A concrete with $10 \mathrm{~mm}$ crushed aggregate was used in the beams, so $G_{C I}$ was assumed to be $0.10 \mathrm{~N} / \mathrm{mm}(0.57 \mathrm{lbs} / \mathrm{in})$. The solid line in Fig. 15a shows the variation in $G_{R}$ vs. $l_{d}$ (crack length) for an interface crack that initiates at $x_{c}$, at the observed $P_{f}$. The figure shows that $l_{d}$ of $2 \mathrm{~mm}(0.1$ in) would cause debonding here; experiments reported in the literature observed that widening of a flexural crack in the high moment zone forms interface cracks of this magnitude ${ }^{22}$. The dashed lines in Fig. 15a show that, if the debonding initiated at distances $1 / 2 h$ and $h$ away towards the nearest beam end, much longer cracks of lengths 3.5 and $6 \mathrm{~mm}(0.14$ and 0.23 in) respectively, would be required to cause debonding at the observed $P_{f}$; so these are less likely to occur. The conditions needed for debonding to initiate at $x_{c}$ at $90 \%$ of $P_{f}$ is also investigated in Fig. 15b, and the figure shows that $l_{d}$ about twice that required at $P_{f}$ would be required here to cause failure; so again is less likely. 


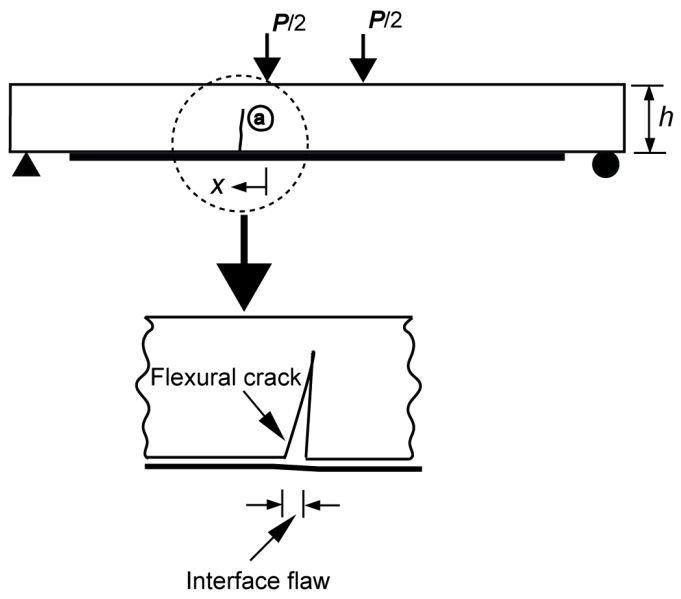

Figure 14 - Initiation of IC debonding by widening of flexural cracks
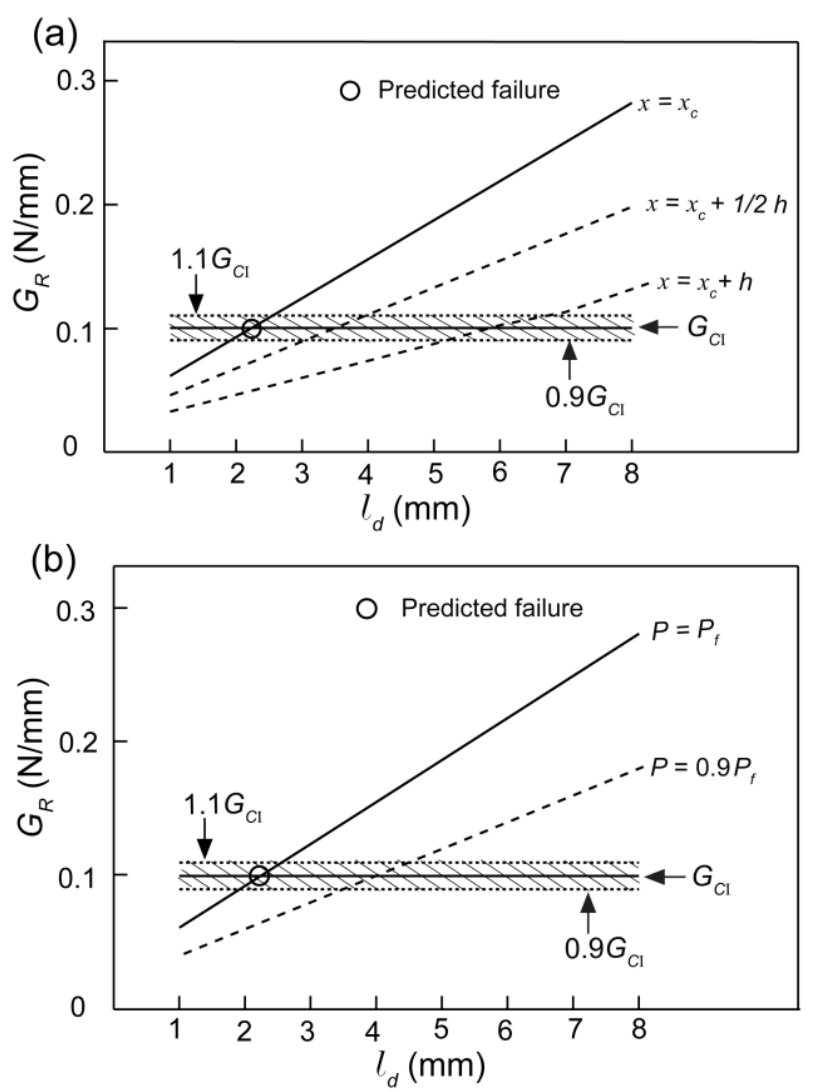

Figure $15-G_{R}$ vs $I_{d}$ plot for Group 1 beam ${ }^{10}$ (a) for fractures starting at different locations (b) $90 \%$ of the failure load

(Energy Release Rate $-0.1 \mathrm{~N} / \mathrm{mm}=0.57 \mathrm{lbs} / \mathrm{in}$; Length $-5 \mathrm{~mm}=0.2 \mathrm{ins}$ ) 
The study has shown that FRP debonding can be studied by means of a global-energy-balance based fracture mechanics model, which obviates the need for a FE analysis of dubious validity. It was necessary to produce a modified form of Branson's model to calculate the energy release during a potential small extension of an existing interface crack. Fracture propagates in the concrete just above the interface and it has been shown that debonding is a Mode I fracture as an average; comparisons with test data validate the assumption.

Despite exact geometries of interface cracks being unknowable, it has been shown that sensible assumptions on likely cracks give comparable predictions with test data. The basis of this work could be effectively used in applications such as the debonding analysis of continuous beams and pre-cracked beams, where external strengthening may be most useful.

Although, model can be used to explain why a particular test beam fails, a comprehensive understanding of the likely sizes and locations of interface cracks is required prior to design. There is thus a significant difference between analysing the mechanism of failure of a laboratory test and designing a beam for use in the real world. The model can however form the basis of a parametric study that could identify the parameters that are most important in controlling debonding, identify how sensitive the failure load is to changes in those parameters, and provide guidance about approximate values of the parameters that should be used when designing beams. Results of this study will be published in due course.

\section{REFERENCES}

1. Achintha, M., and Burgoyne, C. J. (2008). "Fracture Mechanics of Plate Debonding." J. Compos. Constr., 12(4), 396-404.

2. Achintha, M., and Burgoyne, C. J. (2009). "Moment-Curvature and Strain Energy of Beams With External FRP Reinforcement.” ACI Struct. J.,106(1), 2009, 20-29.

3. Achintha, M., and Burgoyne C. J. (2011a). "Fracture Mechanics of Plate Debonding: Validation Against Experiments." Constr. Build. Mater., 25 (6), 2961-2971.

4. Achintha, M., and Burgoyne C. J. (2011b). "Fracture Energy of the Concrete-FRP Interface in Strengthened Beams." Submitted to ACI Structures.

5. Branson, D. E. (1965.) “Design Procedures for Computing Deflections.” ACI J. 65(9), 730-735.

6. Günes, O. (2004). "A fracture based approach to understanding debonding in FRP bonded structural members." Ph.D. thesis, MIT, Cambridge, Mass.

7. Hutchinson, J. W., and Suo, Z. (1992). "Mixed mode cracking in layered materials." Adv. Appl. Mech., 29, 63191.

8. Quantrill, R.J., Hollaway, L.C., and Thorne, A.M. (1996). "Experimental and Analytical Investigation of FRP Strengthened Beam Response: Part I.” Mag. Concrete Res., 48(4), 331-342.

9. $\quad$ Teng, J. G., Chen, J. F., Smith, S. T., and Lam, L. (2002) "FRP Strengthened RC Structures," John Wiley \& Sons Publisher, West Sussex, England.

10. Ross, C. A., Jerome, D. M., Tedesco, J. W., and Hughes, M. L. (1999). "Strengthening of Reinforced Concrete Beams With Externally Bonded Composite Laminates.” ACI Struct. J., 96(2), 212-220.

11. Branson, D.E., and Trost, H. (1982). "Unified Procedures for Predicting the Deflection and Centroidal Axis Location of Partially Cracked Nonprestressed and Prestressed Concrete Members." ACI J., 79(2), 119-130. 
12. Spadea, G., Bencardino, F., and Swamy, R. N. (1998). "Structural Behaviour of Composite RC Beams with Externally Bonded CFRP.” J. Compos. Constr., 2(3), 132-137.

13. Alagusundaramoorthy, P., Harik, E., and Choo, C. C. (2003). "Flexural Behaviour of RC Beams with Carbon Fibre Reinforced Polymer Sheets or Fabric.” J. Compos. Constr., 7(4), 292-301.

14. Täljsten, B. (1997). “Strengthening of beams by plate bonding.” J. Mater. Civ. Eng., 9(4), 206-212.

15. Karihaloo, B. L., Abdalla, H. M., and Imjai, T. (2003.) "A Simple Method for Determining the True Fracture Energies of Concrete," Mag. Concrete Res., 55(5), 471-481.

16. Gálvez, J. C., Elices, M., Guinea, G. V., and Planas, J. (1998) "Mixed Mode Fracture of Concrete Under Proportional and Nonproportional Loading," Int. J. Fract., 94(3), 267-284.

17. Guinea, G. V., Planas, J., and Elices, M. (1994). "A General Bilinear Fit for the Softening Curve of Concrete." Mater. Struct., 27(2), 99-105.

18. Reinhardt, H. W. (1985). "Crack Softening Zone in Plain Concrete Under Static Loading." Cem. Concr. Res., $15(1), 42-52$.

19. Gustafsson, P. J, and Hillerborg, A. (1985). "Improvements in Concrete Design Achieved Through the Application of Fracture Mechanics," In Shah S. P. (ed.), Application of Fracture Mechanics to Cementitious Composites, Dordrecht, The Netherlands, 639-680.

20. Bažant, Z. P., and Becq-Giraudon, E. (2001). "Statistical Prediction of Fracture Parameters of Concrete and Implications for Choice of Testing Standard." Cem. Concr. Res., 32(4), 529-556.

21. Fanning, P. J., and Kelly, O. (2001). "Ultimate Response of RC Beams Strengthened With CFRP Plates," J. Compos. Constr., 5(2), 122-127.

22. Garden, H. N., Quantrill, R. J., Hollaway, L. C., Thorne, A.M., and Parke, G. A. R. (1998). "An Experimental Study of the Anchorage Length of Carbon Fibre Composite Plates Used Strengthened Reinforced Concrete Beams," Constr. Build. Mater., 12(4), 203-219.

34 